\title{
RECHAZO CELULAR AGUDO EN MODELO EX VIVO DE XENOTRASPLANTE RENAL CERDO-HOMBRE
}

\author{
A. VEGA VEGA*, D. GARCÍA ALONSO**, A. RAMOS BARRÓN**, F. VAL BERNAL**, \\ G. PINO CHÁVEZ**, M. GÓMEZ FLEITAS**, M. ARIAS RODRÍGUEZ** \\ *Servicio de Urología de la Obra Hospitalaria de Ntra Sra de Regla. León. \\ **Unidad de Xenotrasplante de la Facultad de Medicina de la Universidad de Cantabria. \\ Hospital Universitario Marqués de Valdecilla. Santander (Cantabria).
}

Actas Urol Esp. 28 (2): 106-121, 2004

\section{RESUMEN}

RECHAZO CELULAR AGUDO EN MODELO EX VIVO DE XENOTRASPLANTE RENAL CERDO-HOMBRE

OBJETIVOS: Desarrollo de un modelo ex vivo de perfusión de riñones de cerdo con sangre humana, intentando reproducir el xenotrasplante renal cerdo-hombre, para el estudio de las manifestaciones que se producen una vez evitado el rechazo hiperagudo.

MÉTODO: Perfusión de los riñones de cerdo durante 3 horas con sangre de cerdo (grupo 1; n=5), sangre humana (grupo 2; $n=5$ ), sangre humana decomplementada por calor (grupo 3; n=5), sangre humana deplaquetada por centrifugación (grupo $4 ; n=5$ ), sangre humana inmuonadsobida con proteína A estafilocócica (grupo 5; $\mathrm{n}=5$ ). Las piezas se estudian por microscopía óptica e inmunohistoquímica

RESULTADOS: Rechazo hiperagudo con hemorragia difusa, trombosis y lesiones glomerulares en el grupo con sangre humana sin manipular. Ausencia de rechazo hiperagudo en el resto de los grupos: decomplementada, deplaquetada e inmunoadsorbida, con presencia de rechazo celular agudo con diferentes grados de infiltración intersticial de células mononucleares, en especial en el grupo con sangre inmunoadsorbida.

CONCLUSIONES: El modelo que permite valorar de forma aislada elementos de la respuesta inmune xenogénica cerdo-hombre. La depleción de complemento, plaquetas y xenoanticuerpos protege a los riñones de cerdo del rechazo hiperagudo, observando por primera vez la presencia de rechazo celular agudo en 3 horas, manifestación que suele precisar para su aparición varios días.

PALABRAS CLAVE: Xenotrasplante. Rechazo hiperagudo. Rechazo celular agudo.

\section{ABSTRACT}

CELLULAR ACUTE REJECTION PIG TO HUMAN IN AN EX VIVO RENAL TRANSPLANT MODEL

OBJECTIVE: Ex vivo perfusion model of pig-to-human kidney xenotransplantation to evaluate human antiporcine xenograft rejection once hyperacute rejection (HAR) is avoided.

METHODS: Pig kidneys were perfused for 3 hours with pig blood (group 1; n=5), human blood (group 2; n=5), complement heat innactivated human blood (group 3; n=5), platelet-depleted human blood (group 4; n=5); and xenoreactive natural antibodies (XNA)-depleted human blood (group 5; n=5). Tissue samples were studied with immunoperoxidase techniques.

RESULTS: Pig kidneys perfused with human blood, group 2, showed HAR with interstitial haemorrhage, vascular thrombi and glomerular injury. Pig kidneys perfused with manipulated human blood (groups 3 to 5) had no histologic evidence of HAR, but showed signs of acute cellular rejection with different degrees of interstitial infiltrate of mononuclear cells, specially in the XNA-depleted group.

CONCLUSIONS: The model may be valuable in the isolated evaluation of the elements involved in the pig-tohuman xenorejection. The depletion of complement, platelets and XNA protected porcine kidneys form HAR in our study and allowed the development of an acute cellular rejection, a very unusual fact in this short time, 3 hours.

KEY WORDS: Xenotransplant. Hyperacute rejection. Acute cellular rejection. 
$\mathrm{E}_{\mathrm{p}}^{\mathrm{l}}$ mayor problema en el campo de los trasplantes renales es la escasez de donantes. Esto ha provocado un creciente interés en el uso de animales como donantes de órganos para humanos, el xenotrasplante. La principal barrera en el xenotrasplante, además de las barreras fisiológicas, infecciosas y éticas en su uso, es la respuesta inmune del receptor contra el órgano ${ }^{1,2}$.

A la hora de elegir el animal donante, existe un consenso casi generalizado del uso del cerdo como fuente de órganos. Aunque los primates son más próximos filogenéticamente a los humanos, debido a su escasez, algunos de ellos en peligro de extinción, la gran prevalencia de infecciones transmisibles al hombre, así como las consideraciones éticas en su uso, hacen que se descarten como fuente de órganos. Los cerdos presentan las ventajas de tamaño y fisiología similar a humanos, su gran disponibilidad, menores trabas éticas, la posibilidad de crianza sin patógenos, así como de manipulación genética para expresar genes extrínsecos que disminuyan las barreras inmunes ${ }^{3}$.

La combinación de especies donantes y receptoras en el xenotrasplante hace que éste se divida en dos categorias: "discordantes", entre las que se produciría un rechazo hiperagudo, como es el caso de la combinación cerdo-hombre, debido a la gran distancia filogenética entre ambas; y "concordantes", combinación de especies entre las que no se produce el rechazo hiperagudo ${ }^{4}$.
El rechazo hiperagudo se produce en minutos a horas tras la reperfusión del injerto. Se caracteriza por la presencia de trombosis, hemorragia intersticial y edema, y depósitos de inmunoglobulinas y complemento en el endotelio vascular del órgano ${ }^{5-7}$. Este rechazo se debe a la existencia de anticuerpos naturales xenoreactivos. Se denominan así porque reconocen las células de diferentes especies y están presentes en la circulación sin que exista exposición conocida al antígeno correspondiente ${ }^{8}$. Los anticuerpos naturales en humanos que se fijan a las células del cerdo se dirigen principalmente contra el disacárido galactosa- $\alpha 1-3$ galactosa (Gal $\alpha 1-3 \mathrm{Gal})^{9}$. Este disacárido se expresa en las células de los mamíferos inferiores pero no en hombres y primates del viejo mundo ${ }^{10}$.

Cuando se evita el rechazo hiperagudo se produce el rechazo vascular agudo y posteriormente el rechazo celular y crónico (Fig. 1). Se han encontrado 3 estrategias de probada eficacia en la prevención del rechazo hiperagudo: depleción de anticuerpos xenoreactivos de la circulación del receptor por plasmaféresis, perfusión a través de órgano y por el paso por columnas de adsorción de distinta afinidad hacia el $\alpha$ Gal; depleción o inhibición del complemento; uso de órganos de animales transgénicos que expresan proteínas reguladoras del complemento compatibles con el receptor ${ }^{11}$.

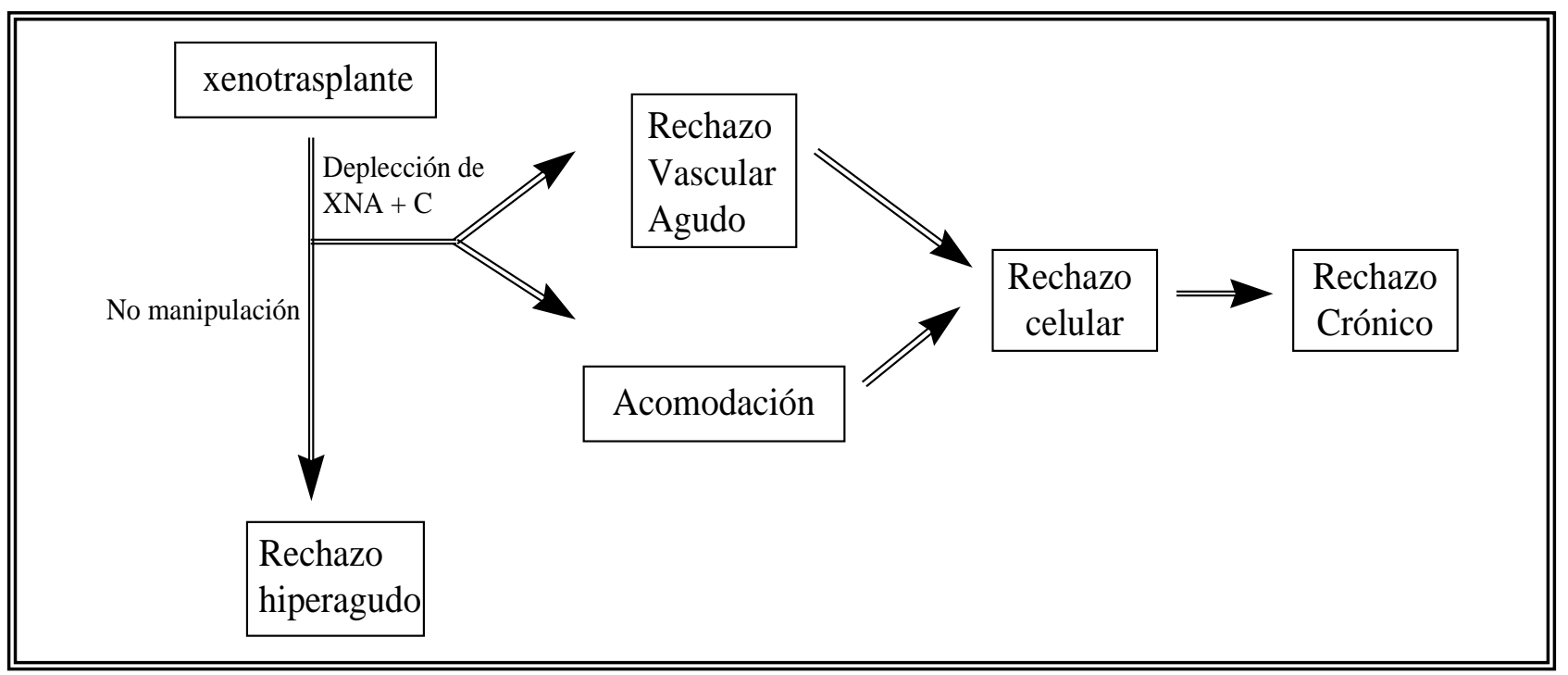

FIGURA 1. Respuesta inmune al xenotrasplante (Platt JL. Approaching the clinical application of xenotransplantation. Am J Med Sci 1997; 313: 315-321. 
Se han desarrollado varios modelos para el estudio del rechazo xenogénico, primero usando pequeños animales, roedores, como receptores y donantes, debido a la accesibilidad de estos modelos. También se ha intentado con grandes animales desde perro y cerdo a primates no humanos. Aunque existen datos útiles procedentes de estos estudios que pueden ser extrapolables al xenotrasplante cerdo-hombre, cada vez parece estar más claro que existen variaciones importantes en las combinaciones especie-especie, en especial en el papel de los anticuerpos xenoreactivos naturales, sistema de complemento y receptores celulares, que pueden influir de una forma decisiva en el rechazo ${ }^{12-15}$.

Para facilitar el estudio del rechazo hiperagudo humano anti-cerdo de una manera especieespecífica se han desarrollado sistemas de perfusión ex vivo que permiten el estudio aislado, en funcionamiento, de los distintos órganos de cerdo prefundidos con sangre humana. Se ha demostrado la validez de estos modelos con los que se pueden reproducir el rechazo hiperagudo ${ }^{16}$, con una respuesta inmunopatológica celular y humoral muy similar a la observada in vivo, pudiendo hacer, además de valorar diferentes aspectos implicados en la respuesta inmune, una medición fisiológica de la función del órgano. La mayor limitación de este estudio es el agotamiento de las respuestas dentro del sistema debido al consumo, pero sí nos permite estudiar de una manera fiable la respuesta inmune inmediata. Nuestro grupo ha desarrollado un modelo experimental de perfusión ex vivo de los riñones de cerdo con sangre humana para el estudio de diferentes factores del rechazo hiperagudo hombre-cerdo, reproduciendo las condiciones in vivo lo más fisiológicamente posible ${ }^{17}$.

\section{MATERIAL Y MÉTODOS}

Animales y técnica quirúrgica

En todo momento el cuidado de los animales se ha efectuado siguiendo las directrices establecidas por la Academia de Ciencias Americana para el cuidado de los animales de laboratorio, publicadas por el Instituto Nacional de la Salud Americano (NIH Publication 86-23, 1985 review). Los experimentos se han hecho en la Unidad de Cirugía Experimental de la Facultad de Medicina de la Universidad de Cantabria, subvencionados por la Fundación Marqués de Valdecilla.

Hemos usado como donantes de órganos cerdos "Large White" de unos 20-25 kilos obtenidos de una granja local. Los cerdos fueron anestesiados con clorhidrato de ketamina, y pentotal sódico y se hizo intubación orotraqueal para ventilación mecánica. La anestesia se mantuvo con besilato de atracurio, cloruro de suxametonio, fentanilo y halotano. Los riñones se extraen en bloque por laparotomía media y se prefunden de forma inmediata con Eurocollins. Se colocan cánulas a nivel de aorta abdominal y cava inferior para la perfusión de los mismos durante el experimento. Se cateterizan los uréteres para la recogida de orina (Fig. 2). Los órganos se conservan a $4^{\circ} \mathrm{C}$ y el experimento se inicia antes de que pasen 3 horas de su extracción.

\section{Descripción del aparato de circulación extracorpórea}

Se construye según el esquema de la Figura 3. Usamos tubos de PVC de $1 / 4$ de pulgada. Una bomba de rodillo (Sarns pediatric roller pump. Sarns Cardiovascular Equipment Inc. Ann Arbor Michigan, USA) impulsa la sangre hacia los riñones, con entrada de sangre por cánula arterial y salida por cánula en la cava. Los riñones del cerdo están en una solución de baño de órganos en una incubadora (Drägerwerk AG, Lübeck, Alemania), a $37^{\circ} \mathrm{C}$ y un $100 \%$ de humedad. Un intercambiador térmico (Casa Reim. Pamplona. España) mantiene la solución de perfusión a $37^{\circ} \mathrm{C}$. El exceso de solución se acumula en un reservorio (Mínimax 1316 Filtered Hardshell Reservoir Medtronic Cardiopulmonary Division, Anaheim USA). La oxigenación se consigue por el oxigenador pediátrico de membrana (Mínimax 1381 Hollow fiber oxygenator Medtronic), que mantiene una saturación constante de $\mathrm{O}_{2}$ del $97 \%$ y un $\mathrm{pH}$ entre 7,35 y 7,55. La presión del circuito se mantiene próxima a $100 \mathrm{mmHg}$, considerada como fisiológica para los riñones, medida por un electrodo conectado en la aorta en la salida de las arterias renales. La producción de orina es medida de forma constante. Antes de conectar los riñones al sistema se recircula la solución 

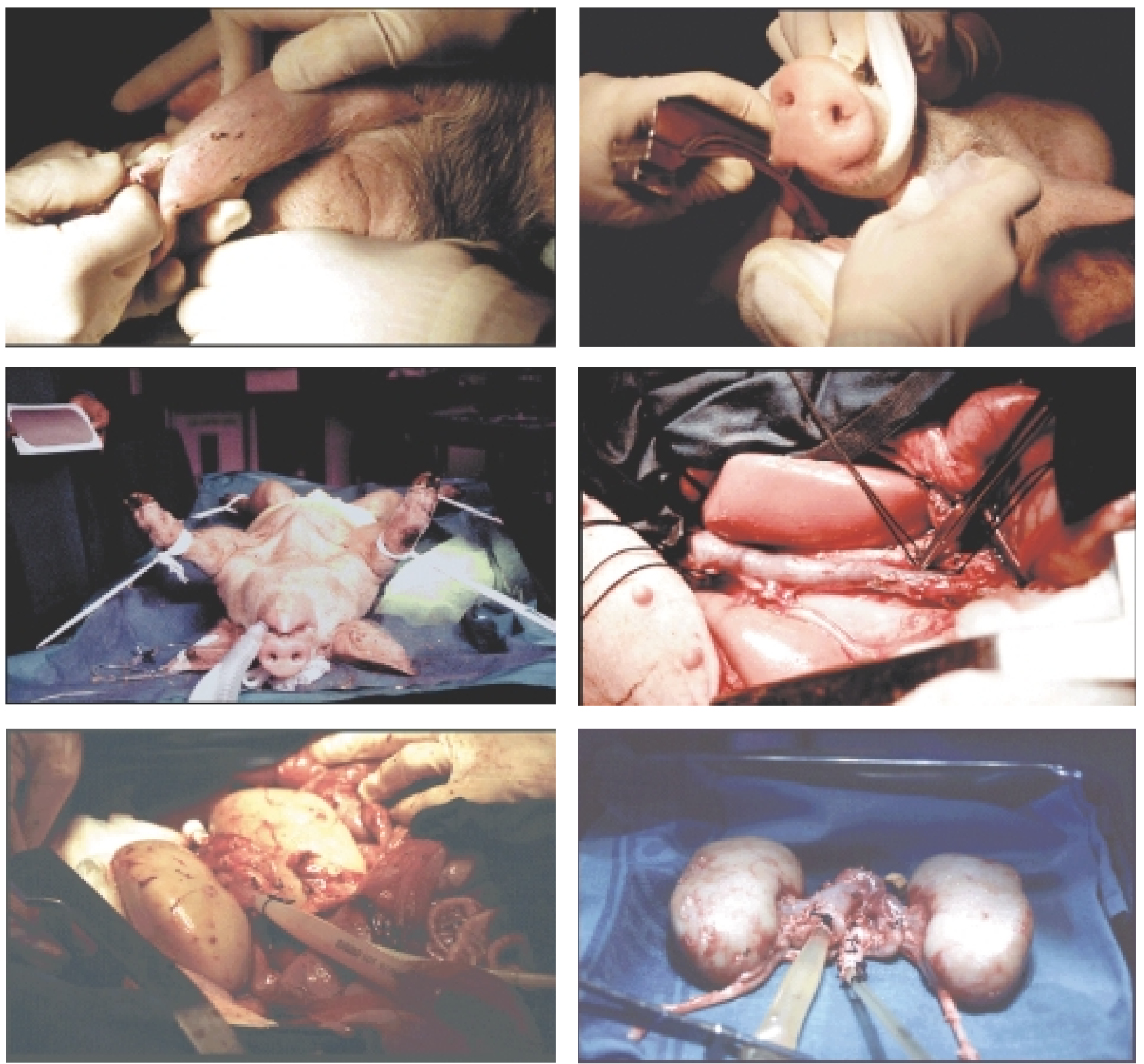

FIGURA 2. Fotos correspondientes a la preparación de la extracción, canulación, perfusión y extracción de los riñones de cerdo.

de perfusión durante 10 minutos. La duración del experimento fue de 3 horas, o hasta que se produjo rechazo hiperagudo.

\section{Solución de perfusión}

La solución de perfusión en este sistema de circulación extracorpórea correspondería al receptor del xenotrasplante. Usamos 5 grupos con 5 experimentos en cada uno: sangre autóloga del cerdo, sangre humana sin manipular, sangre decomplementada, sangre deplaquetada $\mathrm{y}$ sangre inmunoadsorbida.
Todos los donantes de sangre son voluntarios, de ambos sexos y con edades entre 20 y 30 años. Usamos $450 \mathrm{cc}$ de sangre a la que añadimos 150 cc de ringer lactato para conseguir $600 \mathrm{cc}$ con un hematocrito de $30-35 \%$, fisiológico en el cerdo. El tiempo que transcurre desde la extracción de la sangre y su utilización es menor de 3 horas. Durante la perfusión se añade suero, bicarbonato, glucosa, insulina y calcio para mantener estable la osmolaridad, el pH y la concentración de electrolitos. 


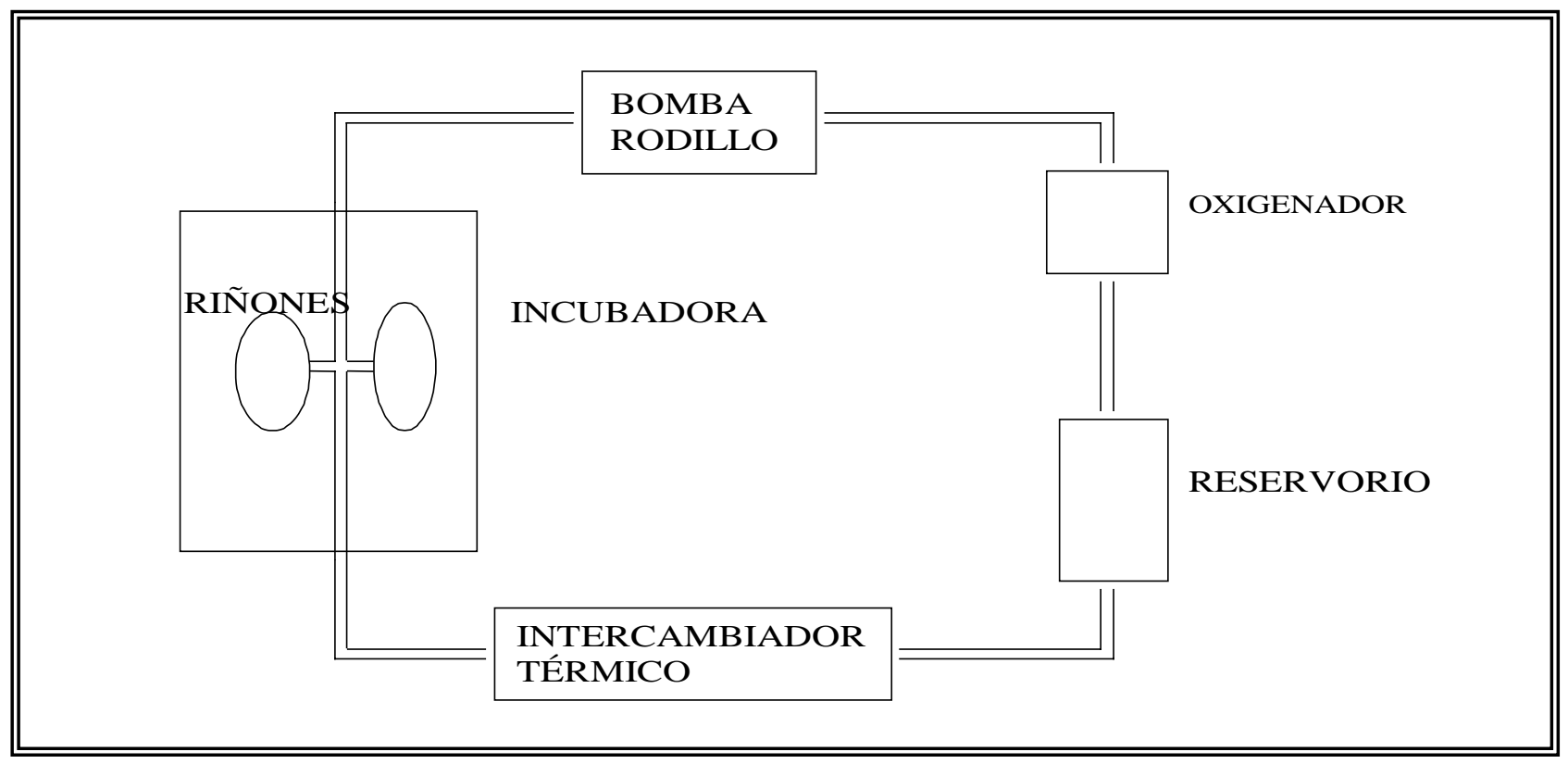

FIGURA 3. Esquema del experimento.

Grupo 1. Sangre autóloga: se recoge del cerdo previo a la extracción de los riñones. Este grupo nos sirve de control de las condiciones del experimento, para definir las alteraciones provocadas por la manipulación y por el sistema de perfusión extracorpórea en el órgano ${ }^{17}$.

Grupo 2. Sangre humana sin manipular: nos sirve como grupo de control ante las distintas manipulaciones de la sangre ${ }^{16}$.

Grupo 3. Sangre humana decomplementada. Separamos el plasma de los componentes celulares por centrifugación (3060 r.p.m. 20 min.) e inactivamos el complemento por calor $\left(56^{\circ} \mathrm{C} 30\right.$ min.), reconstruyendo de nuevo la sangre al final de proceso $^{18}$.

Grupo 4. Sangre humana deplaquetada. Por centrifugación selectiva (1500 r.p.m 9 min. y posteriormente 3500 r.p.m. 20 min.) eliminamos las plaquetas, reconstruyendo de nuevo la solución ${ }^{19}$.

Grupo 5. Sangre humana inmunoadsorbida: consiste en la eliminación selectiva de las inmunoglobulinas plasmáticas mediante la inmunoadsorción tras obtener el plasma por centrifugación (3060 r.p.m. 20 min.) y hacerlo pasar 3 veces por una columna que contiene como ligando proteína A de estafilococo dorado fijada a gel de sepharo$\mathrm{sa}^{20,21}$.

\section{Serología}

Se extrajeron muestras basales y de forma periódica (inicio, 5, 15, 30, 60, 90, 120, $180 \mathrm{~min}$.) de la solución durante la perfusión de los órganos. Se efectuaron las determinaciones gasometría, hemograma y fórmula, iones (potasio, sodio, calcio), proteínas totales, albúmina, creatinina y urea según las técnicas habituales del laboratorio. Además del grupo sanguíneo $\mathrm{ABO}$ y $\mathrm{Rh}$ a los donantes.

Se hicieron determinaciones de las inmunoglobulinas séricas totales IgG e isotipos 1 a 4, e IgM mediante técnicas de ELISA. Los niveles de C3 y C4 se hicieron por nefelometría.

La concentración sérica de xenoanticuerpos se evaluó a partir de una modificación de la técnica ELISA, descrita previamente por Platt et al. ${ }^{22}$. La placa se cubre con células PK-15 de origen porcino que expresan los xenoantígenos. Las células PK-15 se siembran en placas de cultivo de fondo plano de 96 pocillos (Falcon, Becton Dickinson, Co. Mountain View, CA. USA) a la concentración de $8 \times 10.000$ células por pocillo, incubándolas a $37^{\circ} \mathrm{C}$ durante 5-7 días para permitir que formen una monocapa y después se fijan con glutaraldehido (Merck, Darmstaadt, Germany) 0,001\% a $4^{\circ} \mathrm{C}$. Como segundo anticuerpo se emplearon anticuerpos monoclonales de cabra anti-IgG (Sigma) o 
anti-IgM (Sigma) o anticuerpos de ratón anti-isotipo IgG (The Binding Site). Los resultados se expresan en $\mathrm{ng} / \mathrm{ml}$ referidos a una curva estándar obtenida a partir de un pool de sueros de donantes humanos y calibrada con un suero de referencia amablemente cedido por el Dr. Platt.

\section{Histología}

Se toman muestras de ambos riñones para su estudio inmunohistoquímico al final del experimento y se conservan a $-70^{\circ} \mathrm{C}$. Además se obtienen muestras de ambos riñones tras conservación en formol 24 horas e incluirlas en parafina.

\section{Microscopía óptica}

Las muestras histológicas fijadas en formol se tiñen con hematoxilina-eosina, ácido periódico de Schiff (PAS) y tricrómico de Masson según técnica habitual. Los cortes fueron examinados por al menos dos patólogos. En el riñón se valoró la presencia o ausencia de rechazo hiperagudo con un máximo de 3 cruces cuando las lesiones son muy evidentes y un mínimo de 0 cruces cuando no se detectan. El rechazo hiperagudo se valora por la presencia de hemorragia, trombosis o destrucción glomerular.

Inmunohistoquímica de las muestras en parafina

Las secciones histológicas de las biopsias renales embebidas en parafina se incubaron durante dos minutos en una olla a presión con buffer citrato a pH6, se incubaron con el anticuerpo primario frente a CD3, CD20 o CD68 (Dako) 25 min. y se tiñeron en el inmunoteñidor automático Tecnetate 500-220 (Santa Bárbara Ca, USA).

Inmunoperoxidasa de las muestras congeladas

Hemos determinado por inmunohistoquímica en las muestras congeladas los siguientes parámetros:

1. Depósito de complemento (C3 y complejo de ataque de membrana C5b9).

2. Depósito de inmunoglobulinas IgG e IgM.

3. Depósito de fibrina.

4. Identificación de los depósitos celulares con las tinciones para las células B (CD20), células $\mathrm{T}(\mathrm{CD} 2, \mathrm{CD} 4, \mathrm{CD} 8)$ y macrófagos (CD68).
Las muestras congeladas se tiñeron por inmunoperoxidasa con el complejo avidin-biotina. Las criosecciones de $5 \mu \mathrm{m}$, se incubaron de forma secuencial: $10 \mathrm{~min}$. en suero de conejo (the binding site), con antisuero primario de conejo durante 30 min., con inmunoglobulinas de conejo anti-rata marcadas con biotina (Dako) 30 min., $\mathrm{y}$ se incubaron con reactante $\mathrm{ABC}$ (kit procedente de Zymed). Tras lavar con agua se contrasta con hematoxilina carazzi. Para evitar la reacción cruzada con el tejido de cerdo, el reactante $\mathrm{ABC}$ y DAB se hizo con un $1 \%$ de suero porcino (the binding site).

Los antisueros empleados fueron: anticuerpos monoclonales producidos en ratón frente C3 humano (Dako), C5-9b humano (Serotec UK), IgG humana (Dako), IgM humana (Dako), fibrina humana (Dako), CD2 humano (Dako), CD4 humano (Dako), CD8 humano (Dako), CD68 humano (Dako) y células NK humanas (Dako).

\section{Tinción triple para inmunofluorescencia}

Por esta técnica se determinan los depósitos de células $\mathrm{T}$ (CD13), monocitos (CD14) y células NK (CD16).

Es una técnica de inmunofluorescencia múltiple. Permite la localización de 3 lugares antigénicos dentro de una sola sección de tejido. Cada anticuerpo se usa conjugado a diferentes fluorocromos. La inmunofluorescencia permite la localización de varios anticuerpos en la misma célula. Sólo puede usarse en muestras congeladas. Las secciones han de ser de buena calidad y cortadas en cristales de poli-1-lisina.

Proceso: lavar las secciones con agua para disolver el OCT. Lavar con PBS las secciones 3 $\mathrm{x} 5 \mathrm{~min}$. Incubación con anti-human CRIS-7 CD3 FITC (Cymbus Biotech. U.K.) durante 30 min. Lavar de nuevo con PBS ( 3 x 5 min.). Incubar con anti-human CD14 PE (Becton Dickinson U.K.) 1/5 $30 \mathrm{~min}$. Lavar con PBS (3 x 5 min.). Incubación con anti-human CD16 CyChrome (Pharmingen U.K.) 1/5 $30 \mathrm{~min}$. Lavar con PBS ( 3 x 5 min.). Lavar con agua, cubrir con glicerol al $2 \%$ en PBS. Sellar los bordes con parafina y una vez finalizado el proceso se puede observar con el microscopio Olimpus para fluorescencia. 


\section{RESULTADOS}

Parámetros hematológicos y bioquímicos

Hemos analizado una serie de parámetros que nos han servido como control del correcto funcionamiento del sistema, ausencia de pérdidas de la solución de perfusión y para valorar la función de los riñones prefundidos. Los valores no muestran grandes variaciones entre el inicio $\mathrm{y}$ el final del experimento. Valores iniciales y finales de: hematocrito (30 a 26\%), hematíes (3,3 a $\left.2,7 \mathrm{mill} / \mathrm{mm}^{3}\right)$, hemoglobina $(10,5$ a 9,7 $\mathrm{mg} / \mathrm{dl})$, proteínas $(3,2$ a 3,05 g/dl). La urea y la creatinina disminuyen progresivamente, en especial en los riñones prefundidos con sangre autóloga, indicando un buen funcionamiento de los riñones prefundidos.

\section{Parámetros físicos del sistema}

Hemos tomado como presión fisiológica renal $100 \mathrm{mmHg}$, que se ha mantenido mediante variaciones de flujo. $\mathrm{El}$ aumento de la presión es un signo de rechazo, en el grupo de riñones prefundidos con sangre total se ha alcanzado niveles de 280 $\mathrm{mmHg}$, en el resto de los grupos al no producirse el rechazo se mantiene en $100 \mathrm{mmHg}$ (Gráfico 1).

Con el flujo regulamos la presión. En un inicio se disminuye para mantener la presión por la vasoconstricción inicial. El único que mantiene un bajo flujo es en el que se produce rechazo.

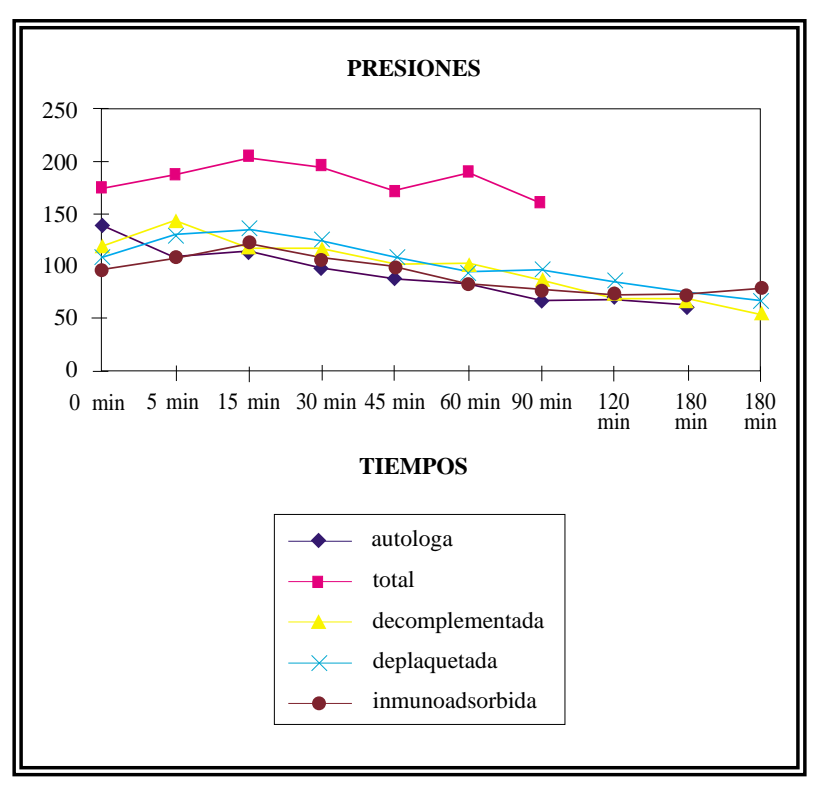

GRÁFICO 1. Presiones en mmHg del sistema en los diferentes grupos durante el experimento.
Eficacia de los procesos de decomplementación, deplaquetación e inmunoadsorción

En el grupo de sangre decomplementada, los niveles de $\mathrm{C} 3$ y $\mathrm{C} 4$ disminuyen respectivamente al 46 y $40 \%$ de sus niveles iniciales.

En el grupo de sangre deplaquetada, las plaquetas disminuyen después del proceso de las 260.000 plaquetas $/ \mathrm{mm}^{3}$ iniciales a 80.000 plaquetas $/ \mathrm{mm}^{3}$.

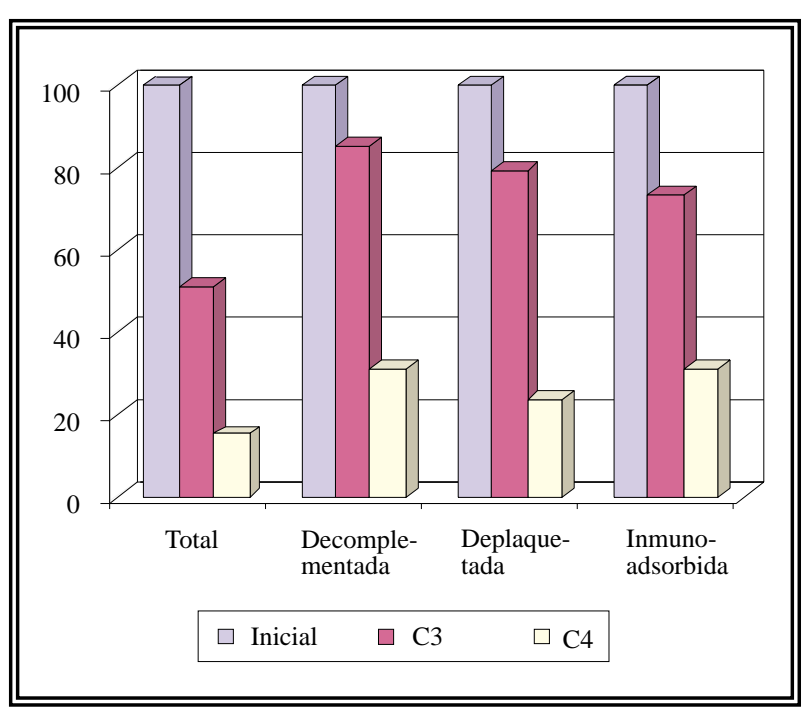

GRÁFICO 2. Consumo de complemento, C3 y C4, a los 30 min. en los distintos grupos del experimento. La primera barra representa el $100 \%$ al inicio del experimento tanto del C3 como del C4 a los 0 min, con fines comparativos.

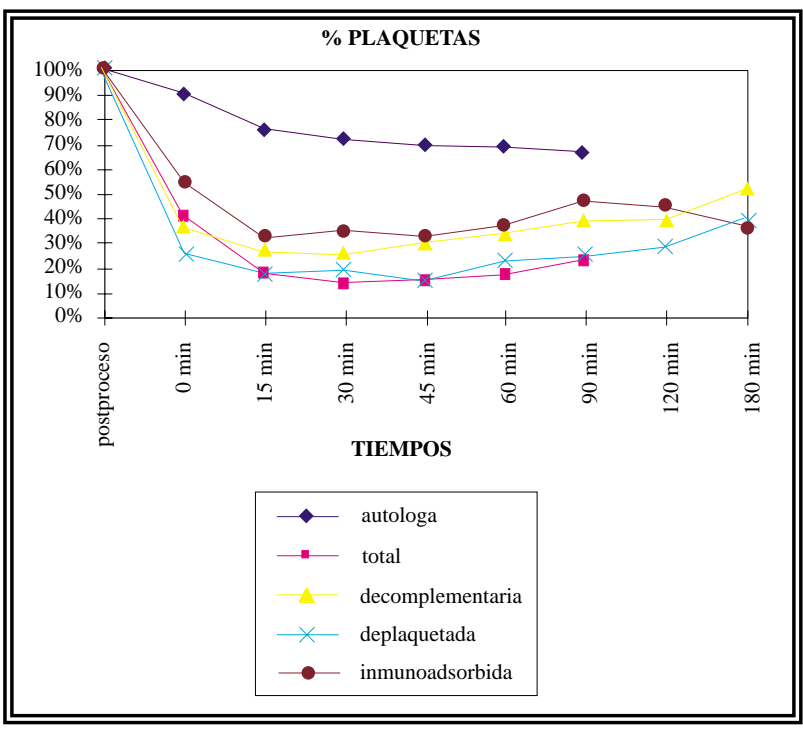

GRÁFICO 3. Porcentaje del número de plaquetas en los distintos grupos durante el experimento, considerando el valor $100 \%$ al valor de la solución inicial al comentzar el experimento. 


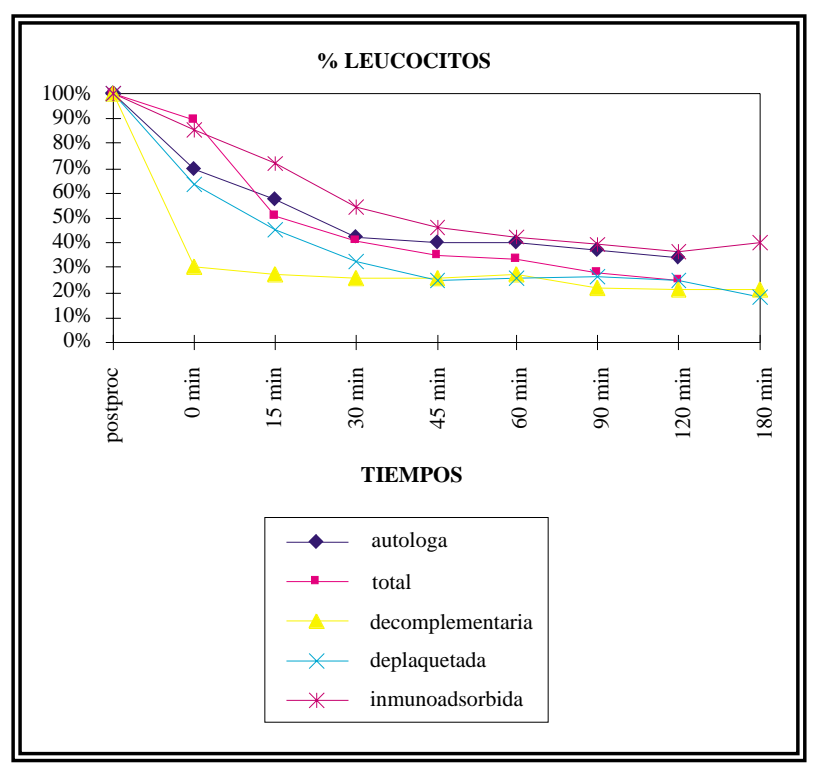

GRÁFICO 4. Porcentaje de leucocitos de los distintos grupos durante el experimento, considerando el $100 \%$ al valor inicial de la solución al comenzar el experimento.

La inmunoadsorción disminuye la IgG e IgM totales al 42 y $50 \%$ de sus niveles iniciales y a la IgG e IgM xenogénicas a un 14 y $47 \%$ de sus niveles iniciales.

Aunque no se consigue la desaparición completa del complemento, plaquetas e inmunoglobulinas xenogénicas, sus niveles disminuyen lo suficiente como para evitar el rechazo hiperagudo y no alterar las propiedades del resto de los elementos de la solución de perfusión ${ }^{23}$.

Descripción y cuantificación de los cambios observados durante los experimentos en los elementos involucrados en el rechazo hiperagudo

Hemos de aclarar que consideramos el momento inicial del proceso cuando conectamos los riñones de cerdo al sistema de circulación "ex vivo", las concentraciones de los parámetros analizados en este momento inicial los tomamos con valor del $100 \%$.

\section{Complemento}

Medimos el valor inicial y a los 30 minutos de funcionamiento del sistema de $\mathrm{C} 3$ y $\mathrm{C} 4$ de la solución de perfusión. El C3 disminuye en un $49 \%$ en la sangre completa, un $20 \%$ en la deplaquetada y un $27 \%$ en la inmunoadsorbida. El C4 disminuye en un $85 \%$ en la sangre comple-

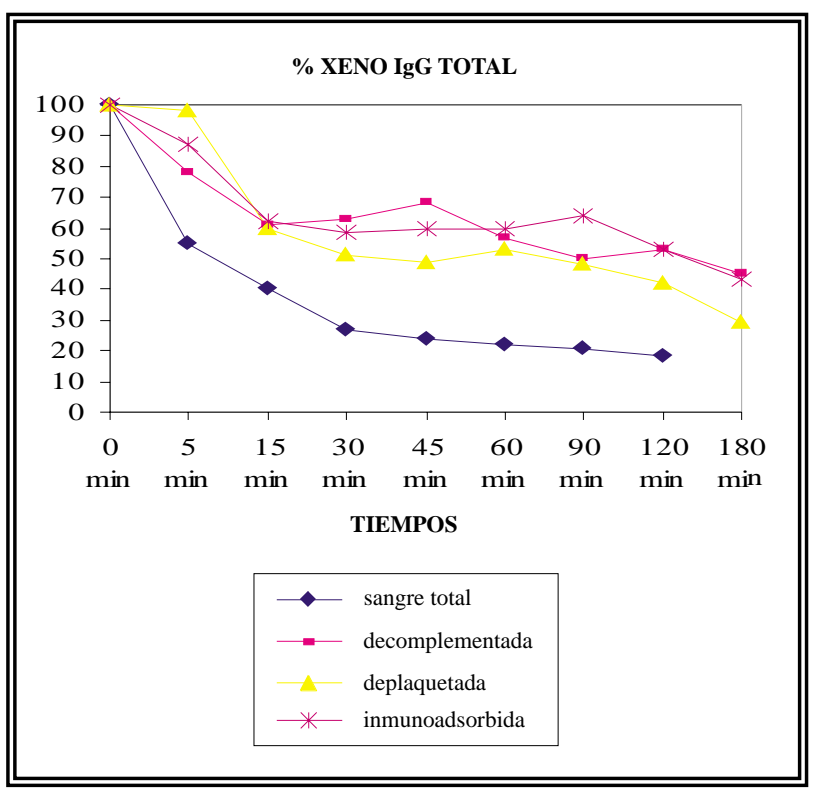

GRÁFICO 5. Variación de los niveles séricos de XenoIgG total durante el experimento en los distintos grupos. Consideramos el valor al inicio del experimento como el $100 \%$.

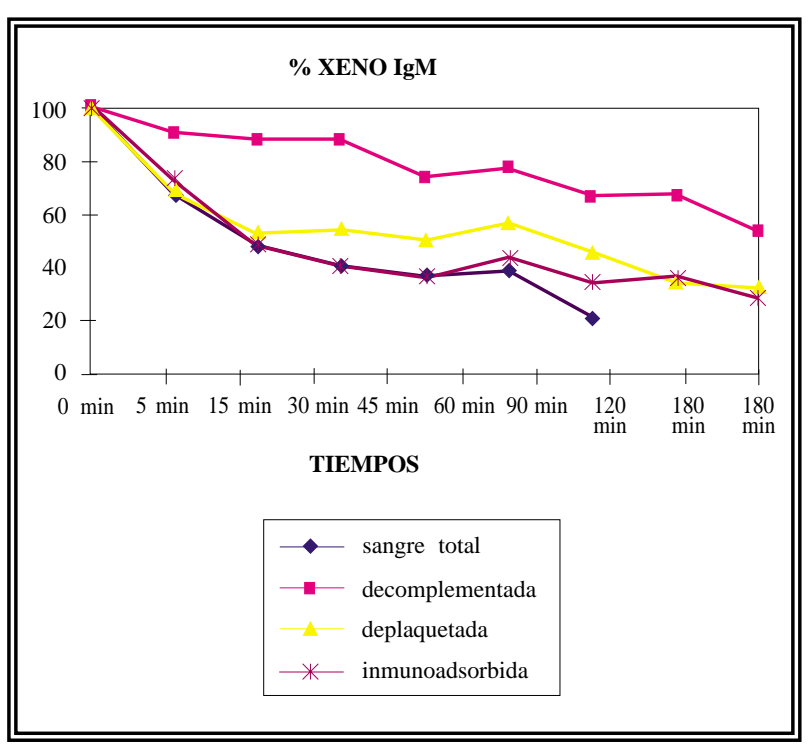

GRÁFICO 6. Variación de los niveles de XenoIgM durante el experimento en los distintos grupos. Consideramos el valor al inicio del experimento como el $100 \%$.

ta, un $76 \%$ en la deplaquetada y un $69 \%$ en la inmunoadsorbida. El grupo con mayor consumo relativo de $\mathrm{C} 3$ es el de sangre completa. El consumo es similar para el C4 en todos los grupos, indicando una activación de la vía clásica del complemento en todos los grupos estudiados en la combinación cerdo-hombre. En el grupo de sangre total se produce tanto una activación de 
la vía clásica como de la vía alterna, observado por un mayor consumo de C3, elemento común en ambas vías (Gráfico 2).

\section{Plaquetas}

Como observamos en el gráfico, no se produce consumo en el grupo de sangre autóloga, las mínimas pérdidas se deben a la adherencia a las superficies del sistema de perfusión, no observamos plaquetas en los riñones prefundidos con esta sangre. En el resto de los grupos existe un gran consumo de plaquetas, siendo mayor en el de sangre total debido a la agregación plaquetaria que se produce en la trombosis extensa observada en este grupo. En los grupos con sangre decomplementada e inmunoadsorbida los niveles de plaquetas se mantienen por encima del 40\% de los niveles iniciales, lo cual concuerda con la histología en la que se observa trombosis ocasional (Gráfico 3).

\section{Leucocitos}

En todos los grupos se produce un descenso similar, debido principalmente a la avidez de éstos por las estructuras sintéticas del sistema, y en parte a la infiltración del órgano. El mayor descenso se produce en los granulocitos, que son los que presentan una mayor avidez por las estructuras del sistema, y el menor el de los linfocitos y monocitos, principales elementos de la infiltración (Gráfico 4).

\section{Inmunoglobulinas totales}

El descenso durante el experimento es mínimo. En el grupo de sangre humana sin manipular, la IgG presenta unos valores finales del 77\% de los iniciales, la IgM el 70\%, por el atrapamiento en los trombos. En el resto de los grupos no se produce descenso.

Inmunoglobulinas xenogénicas

Presentan una gran variabilidad entre los distintos donantes de sangre humana. La IgG xenogénica oscila entre $852 \mathrm{ng} / \mathrm{ml}$ y $5229 \mathrm{ng} / \mathrm{ml}$. La IgM xenogénica oscila entre $2 \mathrm{ng} / \mathrm{ml}$ y 30,7 $\mathrm{ng} / \mathrm{ml}$. No existe relación entre la cantidad de estas inmunoglobulinas y las manifestaciones de rechazo, los mayores niveles no implican un rechazo más precoz.
Niveles de IgG xenogénica

En todos los grupos se produce un descenso acusado de los valores de los xenoanticuerpos naturales IgG, siendo mucho más llamativo en la sangre humana sin manipular, en el grupo que se produce el rechazo hiperagudo. Se hicieron determinaciones de los niveles de los distintos isotipos de IgG xenogénicas (G1, G2, G3 y G4), en todos ellos las disminuciones fueron mucho más marcadas en el grupo de sangre humana sin manipular, esto se debe probablemente al atrapamiento entre los trombos durante el rechazo hiperagudo (Gráfico 5).

\section{Niveles de IgM xenogénica}

Los niveles de xenoanticuerpos tipo IgM descienden en todos los grupos durante el experimento de forma similar, no observándose diferencias entre los distintos grupos (Gráfico 6).

\section{Manifestaciones anatomo-patológicas}

(Tablas I y II)

Riñones perfundidos con sangre autóloga

La sangre usada en este grupo pertenece al cerdo del que se extraen los riñones, nos sirve como control para valorar las lesiones en la extracción, preservación, manipulación de los riñones y las debidas al uso de un sistema de perfusión ex vivo. En todos los experimentos de este grupo macroscópicamente se observa una buena perfusión durante las 3 horas del experimento.

A nivel microscópico observamos una preservación de la arquitectura renal con ligeras manifestaciones de la manipulación: parálisis capilar glomerular, isquemia tubular y focal con pequenos focos de hemorragia intersticial ocasional (Fig. 4a).

Riñones perfundidos con sangre humana sin manipular

Observamos signos de rechazo desde el inicio del experimento, primero petequias hemorrágicas, cada vez más difusas hasta transformarse en una trombosis generalizada del órgano (Fig. 5a). Se suspende el experimento por rechazo hiperagudo a $\operatorname{los} 30,40,90,90$ y 110 minutos.

A nivel microscópico se observa una imagen típica del rechazo hiperagudo: trombosis glome- 
TABLA I

RESUMEN DE LOS HALLAZGOS ANÁTOMO-PATOLÓGICOS DE LOS EXPERIMENTOS

\begin{tabular}{|c|c|c|c|c|c|c|c|}
\hline \multirow{2}{*}{ Grupo/Sangre } & \multirow{2}{*}{ Tiempo } & \multicolumn{3}{|c|}{ R. Hiperagudo } & \multicolumn{3}{|c|}{ R. Celular } \\
\hline & & $\mathrm{A}$ & $\mathrm{B}$ & $\mathrm{C}$ & $\mathrm{D}$ & $\mathrm{E}$ & $\mathrm{F}$ \\
\hline Autóloga & $180^{\prime}$ & No & $+/-$ & No & No & No & $100 \%$ \\
\hline Humana $(\mathrm{H})$ completa & $30-90$ & +++ & +++ & +++ & No & No & $0 \%$ \\
\hline H. decomplementada & $180^{\prime}$ & No & + & No & +++ & ++ & $40 \%$ \\
\hline H. deplaquetada & $180^{\prime}$ & No & $+/-$ & No & ++ & + & $75 \%$ \\
\hline H. inmunoadsorbida & $180^{\prime}$ & No & $+/-$ & No & ++ & + & $25 \%$ \\
\hline
\end{tabular}

A (hemorragia); B (trombosis); C (destrucción glomerular); D (células mononucleares); E (macrófagos); F (ausencia de rechazo)

\section{TABLA II}

RESULTADOS DE LA INMUNOHISTOQUÍMICA EN LOS DISTINTOS GRUPOS: AUTÓLOGA, SANGRE HUMANA COMPLETA, DECOMPLEMENTADA, DEPLAQUETADA E INMUNOADSORBIDA. LOS GRADOS VAN DESDE AUSENCIA DE TINCIÓN (-) A MUY POSITIVA (+++)

\begin{tabular}{|c|c|c|c|c|c|}
\hline Marcadores & Autóloga & $\begin{array}{c}\text { Sangre H } \\
\text { sin manip. }\end{array}$ & Decomplementada & Deplaquetada & Inmunoadsorbida \\
\hline $\mathrm{C} 3$ & - & +++ & - & ++ & ++ \\
\hline C5b9 & - & +++ & - & + & $+/-$ \\
\hline IgG & - & +++ & +++ & +++ & - \\
\hline IgM & - & +++ & +++ & +++ & + \\
\hline $\mathrm{CD} 2$ & - & $+/-$ & + & $+/-$ & - \\
\hline $\mathrm{CD} 4$ & - & - & - & - & - \\
\hline CD8 & - & + & $+/-$ & - & - \\
\hline $\mathrm{CD} 20$ & - & - & - & - & - \\
\hline Fibrina & - & ++ & - & - & - \\
\hline $\mathrm{CD} 68$ & - & + & + & $+/-$ & - \\
\hline $\mathrm{CD} 13 / \mathrm{CD} 14 / \mathrm{CD} 16$ & $-/-/-$ & $-/-/+$ & $++/+/++$ & $-/-/-$ & $-/+/+++$ \\
\hline
\end{tabular}

rular extensa, presencia de hemorragia tubular e intersticial multifocal, focos de isquemia tubular con necrosis, ausencia de revestimiento endotelial a nivel glomerular, pero conservando la membrana basal. No se observa infiltrado por células mononucleares a nivel intersticial, únicamente en los márgenes de los vasos (Fig. 4b).

Observamos depósitos intensos de C3 y del complejo terminal del complemento, también de IgG e IgM en el endotelio vascular. Los depósitos celulares perivasculares son de linfocitos $\mathrm{T}$, en especial CD8+, y de macrófagos y más escasos de células NK.
Riñones perfundidos con sangre decomplementada

Observamos una buena perfusión de los riñones sin signos de rechazo macroscópico (Fig. 5b).

A nivel microscópico no se observan signos de rechazo hiperagudo. La presencia constante de trombosis arteriolar con microtrombosis, indica la existencia de un rechazo humoral. Además, la presencia de infiltrado celular y de tubulitis y lisis tubular indica la coexistencia de rechazo celular y humoral en este tipo de experimentos. El grado de intensidad de rechazo celular fue diferente en los distintos tipos de experimentos (Fig. 4c). 

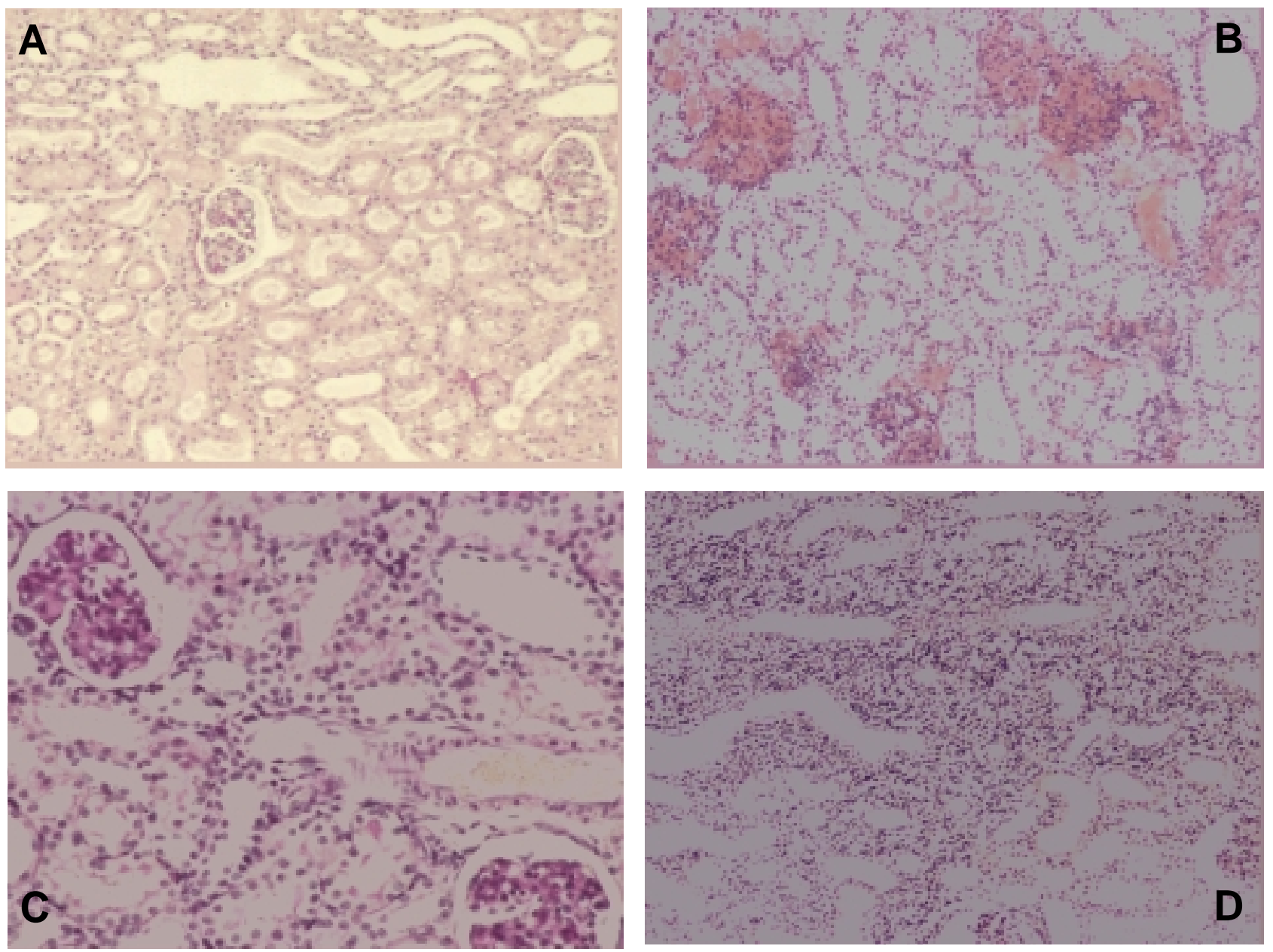

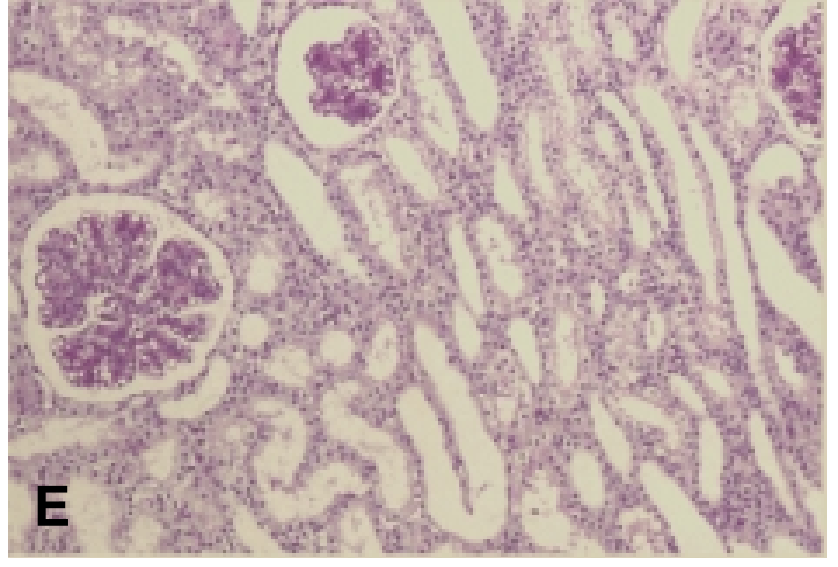

El depósito de complemento es débil o inexistente debido a la decomplementación por calor. Los depósitos de inmunoglobulinas IgG e IgM son tan intensos como en la sangre sin manipular. Los marcadores celulares identifican depósitos de CD8+, macrófagos y células NK (Fig. 6a).
FIGURA 4. Histología de riñones perfundidos (H/E $x$ 25): A) sangre antóloga.

B) sangre humana sin manipular.

C) sangre humana decomplementada.

D) sangre humana deplaquetada.

E) sangre humana inmunoadsorbida.

Riñones perfundidos con sangre deplaquetada

No observamos signos macroscópicos de rechazo en estos experimentos (Fig. 5c).

A nivel microscópico tampoco observamos rechazo hiperagudo en este experimento. En tres de los cinco experimentos no se observó infiltra- 

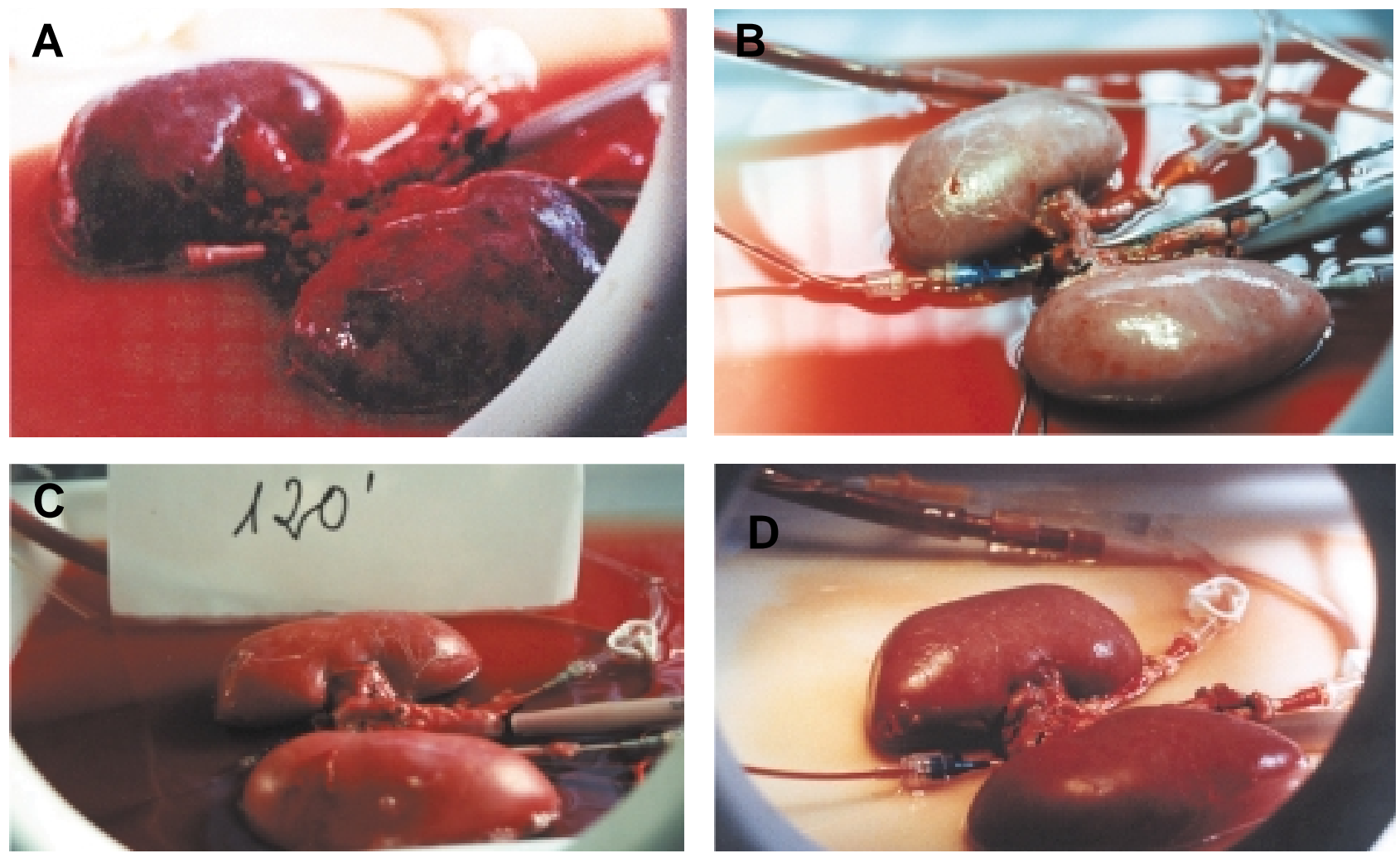

FIGURA 5. Aspecto macroscópico de riñones de cerdo perfundidos con: A) sangre humana sin manipular; B) sangre humana decomplementada; C) sangre humana deplaquetada; D) sangre humana inmunoadsorbida.

ción celular intersticial aunque sí marginación de las células mononucleares en las luces de los capilares glomerulares. En los otros dos experimentos se observaron infiltrados túbulo-intersticiales multifocales de células mononucleares, menos evidentes que en el caso de sangre decomplementada, con presencia de tubulitis y lisis tubular, indicadores de rechazo celular (Fig. 4d).

Los depósitos de complemento son menores que en el caso de sangre sin manipular. Los depósitos de IgG e IgM son igual de marcados que en los dos grupos anteriores. En los casos que existe infiltración celular esta es por linfocitos $\mathrm{T}$ y macrófagos (Fig. 6b).

Riñones perfundidos con sangre inmunoadsorbida

Ausencia de rechazo macroscópico en las 3 horas del experimento (Fig. 5d).

A nivel microscópico no se observa rechazo hiperagudo. Todos los experimentos presentan trombosis capilar glomerular ocasional, con hiperplasia celular mesangial importante. Exis- tencia de un infiltrado celular difuso, con tubulitis y glomerulitis, indicativo de la presencia de rechazo celular agudo. Observamos las manifestaciones típicas de rechazo celular con ausencia de rechazo humoral, es el grupo de experimentos en el que la infiltración celular es más prominente, y estas células están produciendo reacciones inmunes al tener signos de tubulitis (Fig. 4e).

Es el grupo en el que se observa menor depósito de inmunoglobulinas, en especial de IgG, probablemente debido a la inmunoadsorción. Débil positividad para el complemento por precisar de inmunocomplejos para su fijación al endotelio. La infiltración celular es fuertemente positiva para las células NK y más escasa para células $\mathrm{T}$ y monocitos (Fig. 6c).

\section{DISCUSIÓN}

Los órganos vascularizados de cerdo en contacto con sangre humana producen rechazo hiperagudo en minutos a horas, este rechazo está mediado por anticuerpos naturales preformados, la cascada del complemento, las células inflama- 
torias y el endotelio del cerdo cen $^{1,24,25}$. Para valorar la participación de los distintos elementos implicados en el rechazo hiperagudo de una forma especie-específica cerdo-hombre, hemos desarrollado un sistema de perfusión ex vivo de los riñones de cerdo con sangre humana. Los hallazgos en los diferentes estudios de perfusión ex vivo cerdo-hombre demuestran que es un sistema que puede usarse de una forma eficaz y controlada, que nos permite valorar la mayoría de los aspectos implicados en la respuesta inmune precoz, además de una medición fisiológica de la función del órgano ${ }^{16,17,19}$. La validez de nuestro modelo ha quedado demostrada con la producción del rechazo hiperagudo, con una respuesta inmunopatológica celular y humoral similar a la observada in vivo, demostrando su fiabilidad en el estudio de diferentes aspectos del rechazo hiperagudo cerdo-hombre, aunque con las limitaciones de ser un modelo ex vivo, como es el agotamiento inmune ${ }^{16,19}$.

Las condiciones de nuestro modelo de perfusión extracorpórea se ajustaron para que fueran lo más fisiológicas posible con 25 experimentos previos, con riñones perfundidos con la sangre del cerdo del que se extrajeron los riñones. Posteriormente hicimos un grupo de 5 experimentos con riñones de cerdo perfundidos con sangre autóloga. Durante las 3 horas de duración del experimento los riñones mantuvieron una buena perfusión y función con producción de orina inmediata, de características similares a las fisiológicas del cerdo. $\mathrm{El} \mathrm{pH}$ fue constante de 7,4, mantuvo la concentración de proteínas, hematíes/cc, hemoglobina y hematocrito. Las presiones del sistema se mantuvieron próximas a 100 mmHg. El número de plaquetas se mantuvo constante, sin activación ni depósito en el órgano ni secuestro en el sistema. Los leucocitos disminuyeron, en especial los granulocitos y monocitos por adherencia a los biomateriales del sistema.

A nivel histológico al final del experimento se conserva la arquitectura renal, con cambios mínimos debidos a la manipulación del órgano durante la extracción y reperfusión: congestión y estasis a nivel glomerular, microtrombos ocasionales y pequeños focos de hemorragia (Fig. 4a). A nivel inmunohistoquímico no se observa depósito de complemento ni inmunoglobulinas, ni infiltra- ción celular en ninguna de las muestras. Todo lo anterior nos indica un funcionamiento cuasifisiológico del sistema de perfusión, confirmando la validez del mismo.

Hemos usado un grupo de 5 experimentos de riñones de cerdo perfundidos con sangre humana completa como control de la respuesta inmune del sistema. Se produce en todos ellos un rechazo hiperagudo con aumento de presiones hasta $250 \mathrm{mmHg}$, cesación de la producción de orina, ingurgitación de los riñones y trombosis generalizada, teniendo que finalizar los experimentos entre los 30 y 90 min. Esto se traduce en una disminución brusca de plaquetas por la formación de trombos al inicio de la perfusión ${ }^{26}$. A nivel microscópico observamos un rechazo hiperagudo indistinguible del observado in vivo ${ }^{25}$, con trombosis glomerular extensa, hemorragia tubular e intersticial multifocal, con focos de isquemia tubular y necrosis (Fig. 4b). Esto indica que en nuestro experimento se mantiene indemne la respuesta inmune inmediata. A nivel inmunohistoquímico existe un depósito extenso de IgG e IgM xenogénicas en el endotelio del riñón del cerdo, así como de complemento, implicados en el rechazo hiperagudo ${ }^{25}$. Existe depósito perivascular de linfocitos, células $\mathrm{T}$ y macrófagos, pero noinfiltrado intersticial.

Una vez demostrado la conservación de la respuesta inmune cerdo-hombre en nuestro sistema de perfusión ex vivo, hemos manipulado la sangre humana para valorar el efecto en el rechazo hiperagudo en distintos mediadores de la respuesta inmune: decomplementación por calor, deplaquetación por centrifugaciones repetidas, e inmunoadsorción por columnas con proteína A estafilocócica. En ninguno de estos grupos se observó el rechazo hiperagudo en las 3 horas de funcionamiento del sistema, indicando la eficacia de la manipulación para evitar este tipo de rechazo ${ }^{23}$.

Los riñones perfundidos con sangre humana decomplementada mantienen una buena perfusión sin signos de rechazo. A nivel histológico presentan trombosis glomerular y arteriolar escasa, con un infiltrado inflamatorio celular importante, con tubulitis y lisis tubular (Fig. 4c). La presencia de trombosis arteriolar va a favor de la existencia de rechazo humoral y la de tubulitis es 
un indicador de rechazo celular ${ }^{1,2,11}$. No hemos de olvidarnos que la presencia de rechazo hiperagudo y, en caso de evitarlo, la aparición de rechazo celular es un contínuum, se inician de forma simultánea, pero las manifestaciones más precoces y fatales para el órgano del rechazo hiperagudo hacen que no se muestren las características del rechazo celular ${ }^{11}$. En nuestro estudio hemos observado que en este grupo de experimentos existen manifestaciones de ambos procesos, tanto humorales (trombosis arteriolar) como celulares (tubulitis y lisis tubular) debido al retraso del rechazo humoral al disminuir el complemento y a la aceleración al rechazo celular en este modelo experimental. A nivel inmunohistológico se observa una intensa fijación de IgG e IgM xenogénica, no siendo afectadas por la decomplementación. Es muy escasa la fijación del complemento, indicando la eficacia de la decomplementación y el infiltrado celular es de células $\mathrm{T}$ y monocitos y en menor medida de macrófagos.

En el grupo de sangre humana pobre en plaquetas no se observa rechazo hiperagudo y los riñones producen orina durante todo el experimento. A nivel microscópico se observa la presencia de un rechazo celular escaso, con discreta tubulitis e infiltración celular (Fig. 4d). Observamos depósitos de IgG e IgM, y de C3 y de complejo terminal de ataque de membrana. La tinción para células es negativa. La agregación plaquetaria puede llevar al reclutamiento de varios sistemas que parecen estar implicados en el rechazo del xenoinjerto ${ }^{27}$. La disminución de plaquetas hace que sea menor la estimulación de los monocitos y el endotelio, dando como resultado un menor infiltrado inflamatorio y una disminución de las manifestaciones del rechazo celular. Esto indica la importancia de las plaquetas en el rechazo xenogénico tanto en el hiperagudo como en el retardado y celular ${ }^{28}$.

En los riñones perfundidos con sangre inmunoadsorbida tampoco observamos rechazo hiperagudo $^{29}$. Las biopsias muestran imágenes típicas de rechazo celular, sin rechazo humoral, con presencia constante de infiltrado intersticial, tubulitis y glomerulitis ${ }^{11}$ (Fig. 4e). No observamos depósitos de IgG y muy escaso de IgM xenogénica, indicando la eficacia de la inmunoadsorción, sí observamos depósitos de C3 pero no de com- plejo de ataque de membrana. Los depósitos celulares presentan un alto porcentaje de células Natural Killer. Estas células son directamente citotóxicas contra las células endoteliales porcinas, incluso en ausencia de inmunoglobulinas ${ }^{30}$. La acción directa de las células NK y sus propiedades de activación independiente de los mecanismos inflamatorios sugiere que la inhibición del complemento y la depleción de los xenoanticuerpos son insuficientes para prevenir el rechazo retardado del xenoinjerto y que puede ser necesario tanto inhibir la activación de las células endoteliales como la citotoxicidad de las células Natural Killer para prolongar la supervivencia de los xenoinjertos ${ }^{31}$.

Un hallazgo constante en nuestros experimentos es la escasa presencia de fibrina, esto puede deberse al uso de heparina o a la limitación en el tiempo de los experimentos, lo cual evita la evolución con la presencia de fibrina.

En la interpretación de nuestros resultados hemos de tener en cuenta el aumento de la migración de los neutrófilos en los órganos sometidos a perfusión ex vivo ${ }^{32}$. En nuestro experimento aunque se observa la presencia de infiltrado celular esta migración no es inespecífica, ya que no se observa cuando usamos la perfusión con sangre autóloga ni en los que se usa sangre humana sin manipular, en los que se produce rechazo hiperagudo ${ }^{33}$. En los que se observa infiltrado celular este produce reacciones inmunes en el intersticio, propias del rechazo celular como es la presencia de tubulitis ${ }^{1,2,11}$. La lesión del endotelio se favorece con la circulación extracorpórea, pudiendo favorecer su activación inmune, con aumento de moléculas de adhesión que favorecen la marginación y migración de los leucocitos al intersticio del órgano, con la posterior activación inmune de éstos produciendo un rechazo celular.

\section{CONCLUSIONES}

En nuestro estudio hemos puesto a punto un modelo de perfusión extracorpórea que permite el estudio del xenotrasplante renal cerdo-hombre, en el que se ha comprobado por un lado un funcionamiento cuasi-fisiológico con la perfusión de los riñones de cerdo con sangre antóloga y su funcionamiento inmune por la presencia de 

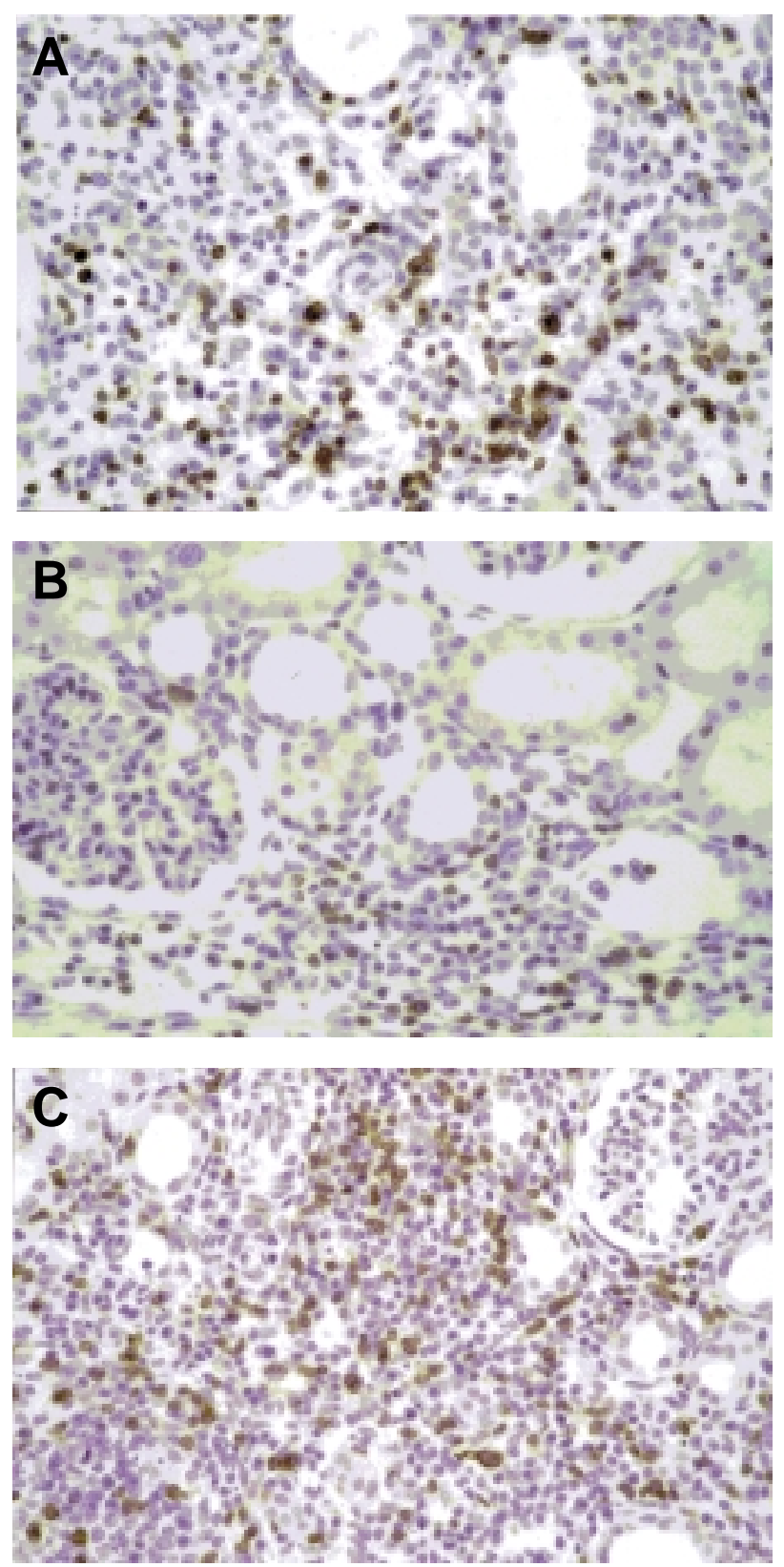

FIGURA 6. Tinciones pan $T \times 100$ de riñones perfundidos con sangre humana: A) decomplementada; B) deplaquetada; C) inmunoadsorbida.

rechazo hiperagudo al prefundir los riñones de cerdo con sangre humana sin manipular, siendo este rechazo indistinguible del observado in vivo. Hemos manipulado la sangre humana usada en la perfusión renal con depleción del complemento, plaquetas y anticuerpos naturales xenoreactivos para evitar el rechazo hiperagudo y para el estudio de las implicaciones de estos elementos aislados en el xenotrasplante renal cerdo-hom- bre. Todas estas manipulaciones han evitado la presencia de rechazo hiperagudo durante las 3 horas que ha durado el experimento. Pero hemos observado la presencia de rechazo celular, en especial en el depleccionado de xenoanticuerpos, lo cual es novedoso por ser tan precoz, en menos de 3 horas; siendo la primera vez que se describe en tan corto espacio de tiempo, lo habitual es que se obtenga después de transcurrir varios días e incluso meses desde el xenotrasplante.

\section{REFERENCIAS}

1. PLATT JL, BACH FH.: The barriers to xenotransplantation. Transplantation 1991; 52: 937-947.

2. SAMSTEIN B, PLATT JL.: Physiologic and immunologic hurdles to xenotransplantation. $J$ Am Soc Nephrol 2001; 12: 182-193.

3. NIEKRASZ M, YE Y, ROLF LJ, ZUHDI N, COOPER DKC.: The pig as a donor for man. Transp Proc 1992; 24: 625-626.

4. CALNE RY.: Organ transplantation between widely disparate species. Transpl Proc 1980; 2: 550-554.

5. BACH FH, ROBSON SC, WINKLER H et al. Barriers to xenotransplantation. Nature Medicine 1995; 1: 869-873.

6. STEVENS RB, PLATT JL.: The pathogenesis of hyperacute xenograft rejection. Am $J$ Kidney Dis 1992; 20: 414-421.

7. SAADI S, PLATT JL.: Transitory perturbation of endothelial integrity induced by antibodies and complement. J Exp Med 1995; 181: 221-231.

8. GRABAR P.: Autoantibodies and the physiological role of immunoglobulins. Immunol Today 1989; 4: 337-340.

9. COOPER DKC, KOREN E, ORIOL R.: Natural antibodies $\alpha$-galctosyl oligosaccharides and discordant xenografting. Xeno 1994; 2: 22-2.

10. GALILI U, SWANSON K.: Gene sequences inactivation of $\alpha 1-3$ galactosyl transferase in catarrhines alter the divergence of apes from monkeys. Proc Natl Acad Sci USA 1991; 88: 7401-7404.

11. BACH FH, AUCHINCLOSS H, ROBSON SC.: Xenotransplantation, en transplantation immunology. Ed Bach FH, Auchincloss H. Philadelphia. Willey-Liss Inc 1995: 305-339.

12. CARTER AS, WELSH KI, MORRIS PJ, FUGGE SV.: Antibodies to human adhesion molecules and their ligands: cross-species reactivity and potentila application in xenotransplantation. Xenotransplantation 1996; 3: 35-42.

13. KIRK AD, LI RA, KINCH MS, ABERNETE KA, DOYLE C, BOLLINGER RR.: The human antiporcine cellular repertorie. Transpl Proc 1993; 25: 447 449.

14. PLATT JL, BACH FH.: Discordant xenografting challenges and controversies. Curr Opin Immunol 1991; 3: 735-739.

15. ROLLINS S, MATIS L.: Cellular interactions in discordant xenotransplantation, en: Xenotransplantation. Ed Cooper DKC, Kemp E, Platt JL, White DJC. 2ª Edición Berlin Springer-Verlag 1997: 190-198. 
16. KIRK AD, HEINLE JS, MAULT JR, SANFILIPPO F.: Ex vivo characterization of human anti-porcine hyperacute cardiac rejection. Transplantation 1993; 56: 785-793.

17. PREMIER ME, SVALNDER CT, HARALDSSON G, BJÖRCK S.: Physiological an histological characterization of a pig kidney in vitro perfusion model for xenotransplantation studies. Scan J Urol Nephrol 1996; 30: 213-221.

18. DUNNING J, BRADLEY PC, WALLWORK KJ, WHITE DJG.: Analysis of hyperacute rejection of pig hearts by human blood using an ex vivo perfusion model. Transplant Proc 1994; 26: 1016-1017.

19. HAN LK, HENRY ML, FERGUSON RM.: The effect of xenoantibody and formed cellular blood elements on ex vivo xenograft hyperacute rejection. Transplant Proc 1991; 23: 574-575.

20. HAKIM RM, MILFORD E, HIMMELFARB J, WINGARD R, LAZARUS M, WATT RM.: Extracorporeal renoval of anti HLA antibodies in transplant candidates. Am J Kidney Dis 1990; 16: 423-431.

21. KROSHUS TJ, DALMASSO AP, LEVENTHAL J, JOHN R, MATAS AJ, BOLMAN III RM.: Antibody removal by column immunoadsorption prevents tissue injury in an ex vivo model pig to human xenograft hyperacute rejection. $J$ Surg Research 1995; 59: 43-50.

22. PLATT JL, TURMAN MA, NOREEN HJM, FISHER RJ, BOLMAN RM, BACH FH.: An ELISA assay for xenoreactive natural antibodies. Transplantation 1990; 49: 1000.

23. JORGENSEN KA, KEMP E, BARFORT P, STARKLINT H, LARSEN S, PUNK-ANDERSEN G.: On the role of platelets and leukocyte in renal xenoperfusion. Acta Path Immunol Scan 1986; 94: 223-227.

24. GACA JG, LESHER A, AKSOY O et al.: Disseminated intravascular coagulation in association with pig-to-primate pulmonary xenotransplantation. Transplantation 2002; 73: 1713-1723.

25. PLATT JL, FISCHEL RJ, MATAS AJ, RIEF SA, BORMAN EM, BACH FH.: Immunology of hyperacute xenograft rejection in a swine-to-primate model. Transplantation 1991; 52: 214-220.
26. ITO S, XAMUSSI G, TETTA C et al.: Hyperacute renal allograft rejection in the rabit: the role of platelet-activating of cationic proteins derived from polymorphonuclear leukocytes and from platelets. Lab Invest 1984; 51: 148-161.

27. HANCOCK WW.: Chemokines and pathogenesis of T-cell dependent immune responses. Am J Pathol 1996; 148: 681-684.

28. BUHLER L, BASKER M, ALWAYN IP et al.: Coagulation and thrombotic disorders associated with pig organ and hematopoietic cell transplantation in nonhuman primates. Transplantion 2000; 70: 1323-1331.

29. BRENNER P, REICHENSPURNER H, SCMOECKEL $M$ et al.: Prevention of hyperacute xenograft rejection in orthotopic xenotransplantation of pig hearts into baboons using immunoadsorption of antibodies and complement factors. Transpl Int 2000; 13: S508-S517.

30. GOODMAN DJ, VON ALBERTONI M, WILLSON A, MILLAN MT, BACH FH.: Direct activation of porcine endotelial cells by human natural killer cells. Transplantation 1996; 61: 161-164.

31. INVERARDI L, SAMARA M, MOTTERLINI R, MANGILI F, BENDER JR, PARDI R.: Early recognition of a discordant xenogeneic organ by human circulating lymphocytes. J Immunol 1992; 149: 1416-1423.

32. STARZL TE, BOHMIG HJ, AMEMIYA $\mathrm{H}$ et al.: Clotting changes, including disseminated intravascular coagulation during rapid renal-homograft rejection. New Eng $J$ Med 1970; 283: 383-390.

33. COLLINS BH, CHARI RS, MAGEE JC et al.: Mechanisms of injury in porcine livers perfused with blood of humans with fulminant hematic failure. Transplantation 1995; 62: 131-137.

Dr. A. Vega Vega

Gran Vía de San Marcos, 42 - 6을

24002 León

(Trabajo recibido el 1 octubre de 2003) 